\title{
The effects of the COVID-19 pandemic on quality of life: a survey of mildly disabled multiple sclerosis patients
}

Amirreza Naseri, ${ }^{1,2}$ Ehsan Nasiri, ${ }^{1,2}$ Malihe Talebi ${ }^{3}$ and Mahnaz Talebi ${ }^{2}$

${ }^{1}$ Student Research Committee, Tabriz University of Medical Sciences, Tabriz, Islamic Republic of Iran. ${ }^{2}$ Neurosciences Research Center, Tabriz University of Medical Sciences, Tabriz, Islamic Republic of Iran (Correspondence to: Mahnaz Talebi: Talebi511@yahoo.com). ${ }^{3}$ Health Center of East Azerbaijan Province, Tabriz, Islamic Republic of Iran.

\begin{abstract}
Background: Almost everyone's health-related quality of life (HQoL) can be affected by a huge health problem like the COVID-19 pandemic.

Aims: We assessed the short-term impact of the COVID-19 pandemic on HQoL in multiple sclerosis (MS) patients in Tabriz, Islamic Republic of Iran.

Methods: A printed version of the MS-specific HQoL questionnaire was completed by patients at the neurology department at the university hospital in Tabriz and the scores before and during the pandemic (2019 and 2020) were compared.

Results: We recruited 50 patients for this study. Although the overall physical (69.29 + SD 16.59, to 68.40 + SD 20.95) and mental health (67.36 + SD 19.02 to $66.76+$ SD 22.70) composite scores decreased slightly in the second stage, however, this change was not statistically significant $(P=0.67, P=0.83)$. The severity of MS was associated with changes in mental and physical health composites.

Conclusions: The effect of the pandemic on the HQoL of mildly disabled MS patients was not statistically significant. Keywords: multiple sclerosis, quality of life, COVID-19 pandemic, health-related quality of life

Citation: Naseri A; Nasiri E; Talebi M; Talebi M. The effects of the COVID-19 pandemic on quality of life; a survey of mildly disabled multiple sclerosis patients. East Mediterr Health J. 2021;27(10):1001-1006. https://doi.org/10.26719/emhj.21.034

Received: 26/11/20; accepted: 01/03/21

Copyright ( C World Health Organization (WHO) 2021. Open Access. Some rights reserved. This work is available under the CC BY-NC-SA 3.o IGO license (https://creativecommons.org/licenses/by-nc-sa/3.o/igo).
\end{abstract}

\section{Introduction}

The coronavirus disease 2019 (COVID-19) pandemic, as the greatest challenge since World War II (1), is a major concern globally in 2020. Multiple sclerosis (MS) itself, is not a risk factor for contracting severe acute respiratory syndrome coronavirus 2 (SARS-CoV-2) (2), but some disease-modifying drugs may reduce the ability of the immune system to respond to an infection, which can make MS patients more susceptible to the disease $(3,4)$.

A study of the evaluation of health-related quality of life (HQoL) reported a significant increase in pain/ discomfort and anxiety/depression factors of the EuroQol-5D instrument in a general Chinese population (5). Another study assessing quality of life (QoL) in cancer patients during the COVID-19 pandemic found that QoL was distinctly affected (6). A QoL survey among 158 Italian patients confirmed the impact of the COVID-19 pandemic on the risk of anxiety/depression in patients with primary antibody deficiencies (7).

Previous studies have indicated that social and family circumstances and physical disability of disease can impact patients' QoL (8-11). Adding other stressors such as disease outbreaks may affect patients' QoL due to fear of the effects of infectious disease on the existing illness and fear of the consequences of changing treatment. The goal of this study was to evaluate the short-term impact of COVID-19 pandemic on HQoL in a sample of MS patients.

\section{Methods}

\section{Study design and ethical issues}

This cross-sectional study was carried out during October 2019-June 2020. Patients were recruited via the neurology department at the university hospital in Tabriz, Islamic Republic of Iran. All of the patients involved in the study gave detailed informed consent before each stage of completing the questionnaire and the study did not impose a financial burden on patients. Adult patients with a definitive diagnosis of relapsing-remitting MS (RRMS) according to the revised 2017 McDonald diagnostic criteria and a lower degree of disability on the Expanded Disability Status Scale (EDSS), score $\leq 4$, were selected for this study. Patients with a history of COVID-19 or any other infectious disease, patients with COVID-19 underlying medical conditions, history of alcohol abuse, changing medication between 2 stages of the study, having corticosteroid pulse or MS relapse within 8 weeks of the assessments, systemic diseases or severe disabilities, and presence of physical impairments that could interfere with HQoL testing were excluded from our sample. At both stages, patients were examined by a neurologist and where there was any change in the EDSS score, they were excluded from our sample. 


\section{Ethical considerations}

The ethics committee of Tabriz University of Medical Sciences reviewed and approved the study protocol (Ethics Code: IR.TBZMED.REC.1399.385).

\section{Data collection}

The first stage of collecting data was carried out between October 2019 and February 2020, before the COVID-19 pandemic as a part of another published study (12); 92 patients were involved in this stage. The second stage was during the COVID-19 pandemic in May and June 2020; in total, 50 patients were involved in this stage. All of the patients who had participated in the first stage of the study and had attended the medical centre for their routine medical visit were involved in this study apart from those who were ruled out according to the exclusion criteria. To reduce the risk of infection, all the hygiene protocols were followed strictly by both the healthcare providers and the patients, during the examination. We used the Farsi version of the MS quality of life-54 (MSQOL-54) questionnaire designed by Vickrey et al. $(10,11,13)$ for measuring HQoL. The validity and reliability of the Farsi translated version of the questionnaire were approved by Ghaem et al. (14). A printed version of the questionnaire was completed by the patients (in the case of disability, a trained colleague helped in reading and completing it). We divided patients into 3 groups according to drug usage: oral, injection and infusion medications. The oral drug group included dimethyl fumarate and fingolid. The injection group included high-dose high-frequency

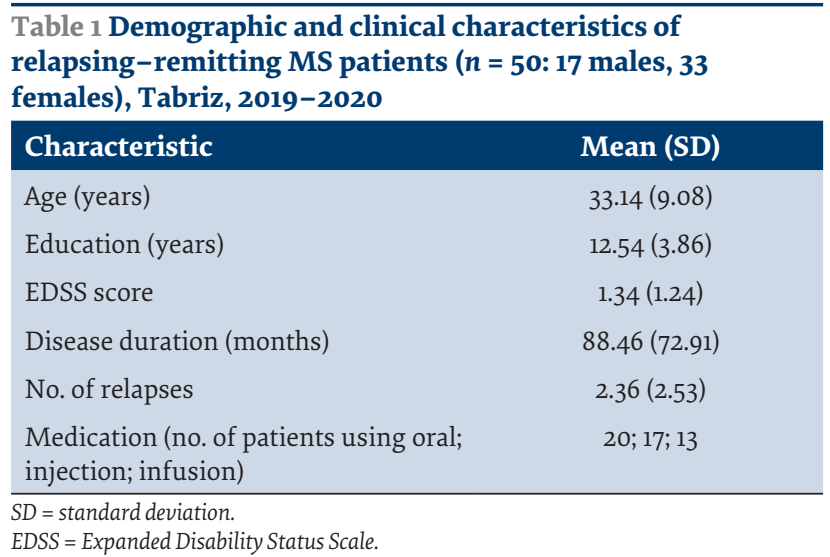

drugs (interferon beta-1a), glatiramer acetate and lowdose low-frequency drugs (interferon beta-1a) and infusion drugs, including natalizumab and rituximab.

\section{Statistical analysis}

The results of the first and the second stages of study were compared by patients themselves using SPSS, version 26.0, with significance level 0.05 and 95\% confidence interval. Values are given as mean and standard deviation (SD) rounded to 2 decimal places and the paired samples t-test was used to compare results before and during the pandemic. The HQoL changes were calculated and the Pearson correlation was used to find the correlation coefficients between demographic factors and absolute values of HQoL changes. For assessment of differences

\begin{tabular}{|c|c|c|c|}
\hline \multirow[t]{3}{*}{ HQoL subscales } & \multicolumn{2}{|c|}{ Score } & \multirow[t]{3}{*}{ P-value ${ }^{a}$} \\
\hline & Before & During & \\
\hline & Mean (SD) & Mean (SD) & \\
\hline \multicolumn{4}{|l|}{ Physical } \\
\hline Physical function & $80.15(22.83)$ & $80.10(24.85)$ & 0.98 \\
\hline Health perceptions & $62.70(19.27)$ & $66.80(20.64)$ & 0.11 \\
\hline Energy/fatigue & $57.12(18.16)$ & $57.44(21.97)$ & 0.91 \\
\hline Physical role limitations & $71.50(37.46)$ & $66.00(40.01)$ & 0.25 \\
\hline Pain & $71.96(20.05)$ & $69.69(26.23)$ & 0.47 \\
\hline Sexual function & $71.98(31.37)$ & $70.83(35.66)$ & 0.83 \\
\hline Social function & $71.50(20.48)$ & $70.99(20.28)$ & 0.86 \\
\hline Health distress & $67.70(25.75)$ & $67.90(28.99)$ & 0.95 \\
\hline \multicolumn{4}{|l|}{ Mental } \\
\hline Overall quality of life & $71.63(20.33)$ & $70.93(21.86)$ & 0.81 \\
\hline Emotional well-being & 59.35 (19.19) & $59.51(21.42)$ & 0.95 \\
\hline Mental role limitations & $67.99(38.07)$ & $67.33(39.54)$ & 0.92 \\
\hline Cognitive function & $76.30(17.43)$ & $72.70(25.39)$ & 0.23 \\
\hline Health distress & $67.70(25.75)$ & $67.90(28.99)$ & 0.95 \\
\hline \multicolumn{4}{|l|}{ Overall } \\
\hline Physical health composite & $69.29(16.59)$ & $68.40(20.95)$ & 0.67 \\
\hline Mental health composite & $67.36(19.02)$ & $66.76(22.70)$ & 0.83 \\
\hline
\end{tabular}

$\mathrm{HQOL}=$ health-related quality of life $\mathrm{SD}=$ standard deviation

${ }^{a}$ Difference was not statistically significant in any subscale in our sample. 
related to sex and medications, the independent samples t-test and one-way ANOVA were used for both demographic factors and HQoL score changes.

\section{Results}

We recruited 50 RRMS patients, 17 males and 33 females. Table 1 gives a summary of the demographic characteristics. Mean age of the participants was 33.14 (SD 9.08; range 19-54) years. Mean duration of illness was 88.46 (SD 72.92) months.

Table 2 gives a summary of the scores on the MSQOL-54 questionnaire subscales before and during the pandemic. Although the overall physical (69.29, SD 16.59, to 68.40, SD 20.95) and mental health (67.36 SD 19.02 to 66.76 SD 22.70) composite scores decreased slightly in the second stage, however, this change was not statistically significant $(P=0.67, P=0.83)$. Some subscales such as physical role limitations $(P=0.25)$, pain $(P=0.24)$ and cognitive function $(P=0.23)$ showed a decline, while health perception $(P=0.11)$ showed an improvement during the COVID-19 pandemic. Generally, none of these changes were statistically significant. Physical function and emotional well-being were the subscales that were the most similar between the first and second stages of the study $(P=0.98, P=0.95)$. The decrease in mental $(P=$

\begin{tabular}{|c|c|c|c|c|c|}
\hline \multirow[t]{2}{*}{ HQoL subscale } & \multirow[t]{2}{*}{ Statistic } & \multicolumn{4}{|c|}{ Component } \\
\hline & & Age & Education & Duration of disease & EDSS score \\
\hline \multicolumn{6}{|l|}{ Physical } \\
\hline \multirow[t]{2}{*}{ Physical function } & $\mathrm{r}$ & 0.20 & -0.03 & 0.46 & 0.48 \\
\hline & $P$-value & 0.15 & 0.78 & $<0.01$ & $<0.01$ \\
\hline \multirow[t]{2}{*}{ Health perceptions } & $\mathrm{r}$ & 0.05 & -0.27 & 0.13 & 0.06 \\
\hline & $P$-value & 0.70 & 0.05 & 0.33 & 0.66 \\
\hline \multirow[t]{2}{*}{ Energy/fatigue } & $\mathrm{r}$ & 0.01 & -0.01 & 0.00 & 0.20 \\
\hline & $P$-value & 0.93 & 0.93 & 0.98 & 0.15 \\
\hline \multirow[t]{2}{*}{ Physical role limitation } & $\mathrm{r}$ & 0.17 & -0.06 & 0.18 & 0.34 \\
\hline & $P$-value & 0.21 & 0.64 & 0.18 & 0.01 \\
\hline \multirow[t]{2}{*}{ Pain } & $\mathrm{r}$ & 0.28 & 0.64 & 0.29 & 0.25 \\
\hline & $P$-value & 0.04 & 0.43 & 0.03 & 0.07 \\
\hline \multirow[t]{2}{*}{ Sexual function } & $\mathrm{r}$ & -0.05 & 0.02 & -0.19 & 0.03 \\
\hline & $P$-value & 0.75 & 0.87 & 0.24 & 0.84 \\
\hline \multirow[t]{2}{*}{ Social function } & $\mathrm{r}$ & -0.16 & -0.15 & -0.03 & -0.00 \\
\hline & $P$-value & 0.26 & 0.27 & 0.81 & 0.96 \\
\hline \multirow[t]{2}{*}{ Health distress } & $\mathrm{r}$ & 0.07 & -0.08 & 0.01 & 0.26 \\
\hline & $P$-value & 0.59 & 0.55 & 0.89 & 0.06 \\
\hline \multicolumn{6}{|l|}{ Mental } \\
\hline \multirow[t]{2}{*}{ Overall quality of life } & $\mathrm{r}$ & 0.10 & -0.22 & 0.28 & 0.33 \\
\hline & $P$-value & 0.48 & 0.11 & 0.04 & 0.01 \\
\hline \multirow[t]{2}{*}{ Emotional well-being } & $\mathrm{r}$ & -0.04 & -0.26 & -0.02 & 0.28 \\
\hline & $P$-value & 0.74 & 0.06 & 0.85 & 0.04 \\
\hline \multirow[t]{2}{*}{ Mental role limitations } & $\mathrm{r}$ & -0.12 & 0.10 & 0.02 & 0.26 \\
\hline & $P$-value & 0.38 & 0.44 & 0.86 & 0.06 \\
\hline \multirow[t]{2}{*}{ Cognitive function } & $\mathrm{r}$ & 0.42 & -0.27 & 0.30 & 0.21 \\
\hline & $P$-value & $<0.01$ & 0.05 & 0.03 & 0.13 \\
\hline \multirow[t]{2}{*}{ Health distress } & $\mathrm{r}$ & 0.07 & -0.08 & 0.01 & 0.26 \\
\hline & $P$-value & 0.59 & 0.55 & 0.89 & 0.06 \\
\hline \multicolumn{6}{|l|}{ Overall } \\
\hline \multirow[t]{2}{*}{ Physical health composite } & $\mathrm{r}$ & 0.06 & -0.09 & 0.26 & 0.35 \\
\hline & $P$-value & 0.64 & 0.50 & 0.06 & 0.01 \\
\hline \multirow[t]{2}{*}{ Mental health composite } & $\mathrm{r}$ & 0.03 & -0.13 & 0.23 & 0.29 \\
\hline & $P$-value & 0.81 & 0.34 & 0.09 & 0.03 \\
\hline
\end{tabular}


o.83) and physical health $(P=0.67)$ composites were not significant either.

A summary of the correlation coefficients for the demographic factors and clinical characteristics of patients with absolute values of changes in the HQoL subscales is presented in Table 3. Age was associated with the pain $(P=0.04)$ and cognitive function $(P<0.01)$ subscale changes. Education did not affect changes in any subscale of HQoL but duration of the disease influenced the physical function $(P<0.01)$, pain $(P=0.03)$, overall QoL $(P=$ $0.04)$ and cognitive function $(P=0.03)$ subscales. Severity of MS according to the EDSS score had an association with physical function $(P<0.01)$, physical role limitation $(P=0.01)$, overall quality of life $(P=0.01)$, emotional wellbeing $(P=0.04)$, and physical $(P=0.01)$ and mental $(P=$ 0.03) health composites changes. Without any significant difference between the demographic characteristics of the female and male participants, the changes in HQoL subscales were not statistically significant in any HQoL subscale (overall score P-values 0.41 and 0.46). Also, comparing types of medication, there was no significant difference in any HQoL subscale between users of oral, injection and infusion disease-modifying drugs (overall score P-values 0.18 and 0.24 ).

\section{Discussion}

The COVID-19 pandemic had negative effects on patients' HQoL but the differences were not statistically significant in our sample. The effects of the COVID-19 pandemic on mental and physical health composites were greater in patients with a higher EDSS score.

A 2020 cross-sectional study in an Iranian setting found that $90 \%$ of MS patients knew that COVID-19 was in the pandemic stage but $27 \%$ did not follow quarantine guidelines strictly (15). It is essential to take the risk seriously, but feelings of anxiety can make people more susceptible to infection. This could be more worrying when we consider the higher rate of anxiety and depression among MS patients $(16,17)$. Nevertheless, the pandemic did not significantly worsen the mental health of the patients in our sample.

MS is not one of conditions that increase the risk of severe illness from COVID-19 $(3,18)$ so health perception showed improvement during the pandemic in MS patients based on the HQL questionnaire. The United
Kingdom MS society advises patients just to practice social distancing and keep washing their hands (19). Italy, the first European country to encounter the effects of COVID-19 pandemic (20), has set up a programme for a compressive response to COVID-19 in patients with MS and achieved reassuring results in the time of the pandemic (21). According to their reports, only 5 of 238 MS patients with symptomatic COVID-19 infection died. All of them had an EDSS score $\geq 6.5$ (22). Also, all 3 cases of COVID-19-positive MS patients in a study in Chile required hospitalization but after a course of treatment they were discharged home and none of them died (23). In our sample, the EDSS score was associated with mental and physical health composites. To keep patients safe and also minimize disease severity, we did not include patients with an EDSS score $>4$ in our study.

A study in Saudi Arabia found 32\% missing hospital appointments and $35.2 \%$ missing drug infusions in MS patients (24). As over $40 \%$ of the COVID-19 infections are hospital-acquired (25), the World Health Organization recommends doctors use telehealth services (26) but there are still some doubts in regard to efficacy (27).

Another concern is medications; the Association of British Neurologists has issued a guideline to assess the safety of using drugs during this pandemic (28). Immunosuppressive drugs can make patients more susceptible to getting infected by SARS-CoV-2 and their use should be reduced as much as possible during the COVID-19 pandemic. In our study, however, differences in type of medication were not associated with any effect of the pandemic on HQoL.

\section{Conclusion}

In conclusion, the COVID-19 pandemic can worsen the HQoL of MS patients but not statistically significantly. The changes in HQoL mental health and physical health composites are associated with severity of MS, but age, education, duration of the disease, sex and type of disease-modifying drugs did not affect these changes.

Funding: This study was supported by the Student Research Committee of Tabriz University of Medical Sciences (Registration code: 65442).

Competing interests: None declared.

\section{Effets de la pandémie de COVID-19 sur la qualité de vie : enquête auprès de patients légèrement handicapés atteints de sclérose en plaques}

\section{Résumé}

Contexte: La qualité de vie liée à la santé (QVLS) de la plupart des personnes peut être affectée par un problème sanitaire de grande ampleur tel que la pandémie de COVID-19.

Objectifs : Nous avons évalué l'impact à court terme de la pandémie de COVID-19 sur la QVLS des patients atteints de sclérose en plaques (SEP) à Tabriz, en République islamique d'Iran.

Méthodes : Une version imprimée du questionnaire sur la QVLS spécifique à la SEP a été remplie par les patients du service de neurologie de l'hôpital universitaire de Tabriz et les scores avant et pendant la pandémie (2019 et 2020) ont été comparés. 
Résultats : Nous avons recruté 50 patients pour cette étude. Même si les scores composites globaux pour la santé physique [69,29, écart type ( $\pm \mathrm{ET}) \quad 16,59$ à $68,40, \pm \mathrm{ET} 20,95]$ et mentale $(67,36, \pm \mathrm{ET} 19,02$ à 66,76, $\pm \mathrm{ET} 22,70)$ ont légèrement diminué au cours de la deuxième phase, ce changement n'était pas significatif $(p=0,67, p=0,83)$. La gravité de la SEP est associée à des changements dans les composites de santé mentale et physique.

Conclusions : L'effet de la pandémie sur la qualité de vie liée à la santé des patients légèrement handicapés atteints de SEP n'est pas statistiquement significatif.
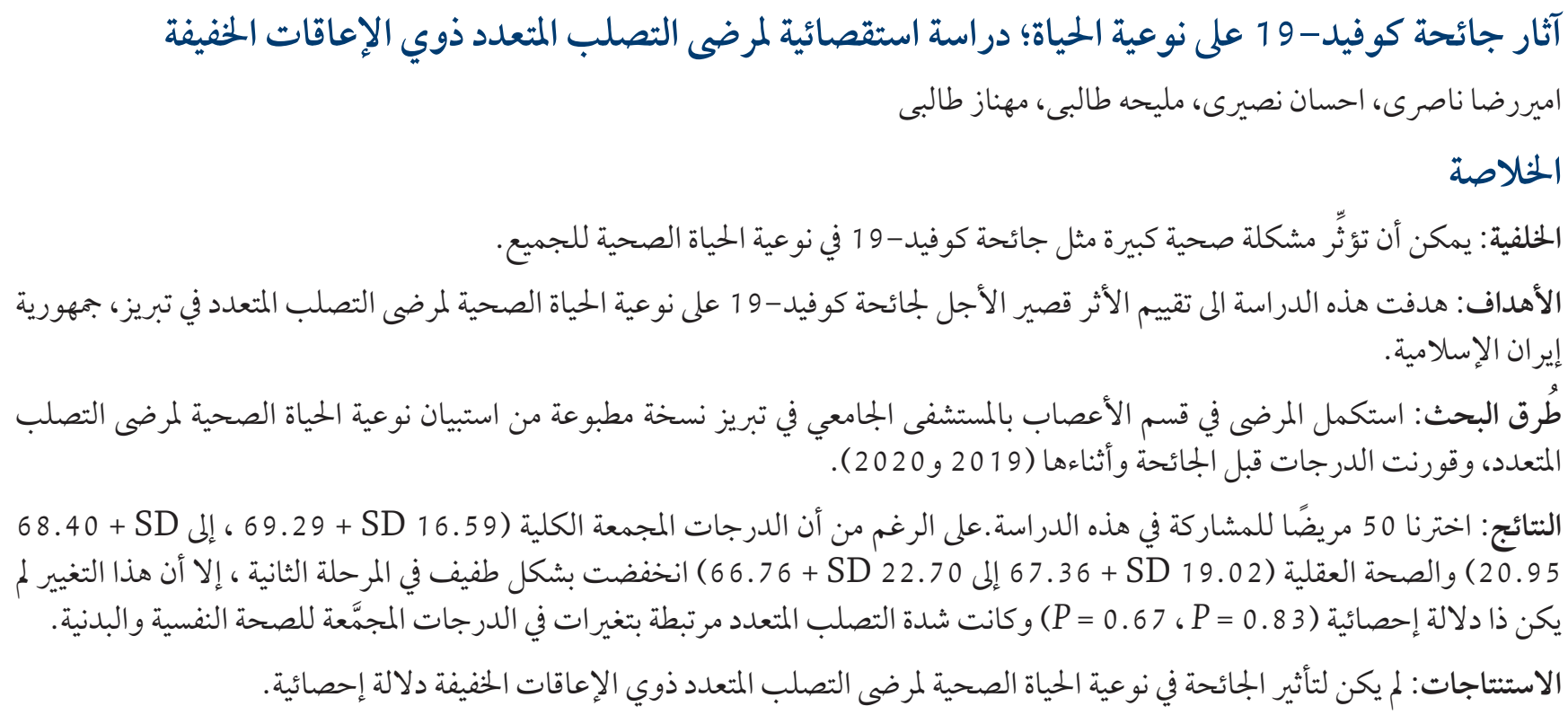

\section{References}

1. COVID-19 pandemic. Humanity needs leadership and solidarity to defeat the coronavirus 2020. New York: United Nations Development Programme; 2020 (https://www.undp.org/content/undp/en/home/coronavirus.html, accessed 10 March 2021).

2. Ghajarzadeh M, Bonavita S. Are patients with multiple sclerosis (MS) at higher risk of COVID-19 infection? Neurol Sci. 2020 Sep;41(9):2315-6. doi:10.1007/s10072-020-04570-8

3. COVID-19: vulnerable and high risk groups. Manila: World Health Organization Regional Office for the Western Pacific; 2020 (https://www.who.int/westernpacific/emergencies/covid-19/information/high-risk-groups, accessed 10 March 2021).

4. Groups at higher risk for severe illness. Atlanta: Centers for Disease Control and Prevention, National Center for Immunization and Respiratory Diseases; 2020 (https://www.cdc.gov/coronavirus/2019-ncov/need-extra-precautions/people-with-medical-conditions.html, accessed 10 March 2021.

5. Ping W, Zheng J, Niu X, Guo C, Zhang J, Yang H, et al. Evaluation of health-related quality of life using EQ-5D in China during the COVID-19 pandemic. PLoS ONE. 2020;15(6):e0234850. doi:10.1371/journal.pone.0234850

6. Ciążyńska M, Pabianek M, Szczepaniak K, Ułańska M, Skibińska M, Owczarek W, et al. Quality of life of cancer patients during coronavirus disease (COVID-19) pandemic. Psycho-Oncology. 2020;29: 1377- 1379. doi:10.1002/pon.5434

7. Pulvirenti F, Cinetto F, Milito C, Bonanni L, Pesce AM, Leodori G, et al. Health-related quality of life in common variable immunodeficiency italian patients switched to remote assistance during the COVID-19 pandemic. J Allergy Clin Immunol Pract. 2020;8(6):1894-9.e2. doi:10.1016/j.jaip.2020.04.003

8. Yalachkov Y, Soydaş D, Bergmann J, Frisch S, Behrens M, Foerch C, et al. Determinants of quality of life in relapsing-remitting and progressive multiple sclerosis. Multiple sclerosis and related disorders. 2019;30:33-7. doi:10.1016/j.msard.2019.01.049

9. Malkova N, Riabukhina O, Babenko L, Ionova T, Kishtovich A. Health-related quality of life in patients with multiple sclerosis. Zh Nevrol Psikhiatr Im S S Korsakova. 2005;105(12):31-7 (in Russian). PMID: 16447564

10. Heiskanen S, Meriläinen P, Pietilä AM. Health-related quality of life-testing the reliability of the MSQOL-54 instrument among MS patients. Scand J Caring Sci. 2007 Jun;21(2):199-206. doi:10.1111/j.1471-6712.2007.00456.x

11. Miller A, Dishon S. Health-related quality of life in multiple sclerosis: psychometric analysis of inventories. Mult Scler. 2005 Aug;11(4):450-8. doi:10.1191/1352458505ms11690a

12. Naseri A, Nasiri E, Talebi M, Karimi K, Talebi M. Does the type of disease-modifying drugs impact on the quality of life in patients with relapsing-remitting multiple sclerosis? Ro J Neurol. 2020;19(3):171-8. doi:10.37897/RJN.2020.3.6 
13. Vickrey B, Hays RD, Harooni R, Myers LW, Ellison GW. A health-related quality of life measure for multiple sclerosis. Qual Life Res. 1995 Jun;4(3):187-206. doi:10.1007/BF02260859

14. Ghaem H, Haghighi AB, Jafari P, Nikseresht A. Validity and reliability of the Persian version of the multiple sclerosis quality of life questionnaire. Neurol India. 2007;55(4):369. doi:10.4103/0028-3886.33316

15. Sahraian MA, Gheini MR, Rezaeimanesh N, Ghajarzadeh M, Moghadasi AN. Knowledge regarding COVID-19 pandemic in patients with multiple sclerosis (MS): a report from Iran. Mult Scler Relat Disord. 2020 Jul;42:102193. doi:10.1016/j. msard.2020.102193

16. Seyed Ahadi M, Sahraian MA, Rezaeimanesh N, Moghadasi AN. Psychiatric advice during COVID-19 pandemic for patients with multiple sclerosis. Iran J Psychiatry Behav Sci.14(2). doi:10.5812/ijpbs.103243

17. Marrie RA, Reingold S, Cohen J, Stuve O, Trojano M, Sorensen PS, et al. The incidence and prevalence of psychiatric disorders in multiple sclerosis: a systematic review. Mult Scler. 2015 Mar;21(3):305-17. doi:10.1177/1352458514564487

18. People with certain medical conditions. Atlanta: Centers for Disease Control and Prevention, National Center for Immunization and Respiratory Diseases; 2020 (https://www.cdc.gov/coronavirus/2019-ncov/need-extra-precautions/people-with-medical-conditions.html, accessed 10 March 2021.

19. Our statement on the coronavirus outbreak. London: MSSociety; 2019 (https://www.mssociety.org.uk/what-we-do/news/covid-19-coronavirus-and-ms, accessed 12 March 2021).

20. Li C, Romagnani P, von Brunn A, Anders H-J. SARS-CoV-2 and Europe: timing of containment measures for outbreak control. Infection. 2020;48(3):483. doi:10.1007/s15010-020-01420-9

21. Sormani MP, Italian Study Group on C-iims. An Italian programme for COVID-19 infection in multiple sclerosis. Lancet Neurol. 2020;19(6):481-2. doi:10.1016/S1474-4422(20)30147-2

22. Sormani MP. An Italian programme for COVID-19 infection in multiple sclerosis. The Lancet Neurol. 2020;19(6):481-2. doi:10.1016/S1474-4422(20)30147-2

23. Ciampi E, Uribe-San-Martin R, Cárcamo C. COVID-19 pandemic: the experience of a multiple sclerosis centre in Chile. Mult Scler Relat Disord. 2020 Jul;42:102204. doi:10.1016/j.msard.2020.102204

24. Alnajashi H, Jabbad R. Behavioral practices of patients with multiple sclerosis during Covid-19 pandemic. PloS One. 2020;15(10):e0241103. doi:10.1371/journal.pone.0241103

25. Wang D, Hu B, Hu C, Zhu F, Liu X, Zhang J, et al. Clinical characteristics of 138 hospitalized patients with 2019 novel coronavirus-infected pneumonia in Wuhan, China. JAMA. 2020;323(11):1061-9. doi:10.1001/jama.2020.1585

26. Implementing telemedicine services during COVID-19: guiding principles and considerations for a stepwise approach: interim guidance. Manila: World Health Organization Western Pacific Region; 2020 (https://wwwcdcgov/coronavirus/2019-ncov/ need-extra-precautions/what-you-can-dohtml, accessed 28 March 2021).

27. Mahmoodpoor A, Akbarzadeh MA, Sanaie S, Hosseini M-S. Role of telehealth in outbreaks-Where the classical healthcare systems fail. Infect Control Hosp Epidemiol. 2020 Aug;41(8):992-4. doi:10.1017/ice.2020.120

28. Coles A, Lim M, Giovannoni G, Anderson P, Dorsey-Campbell QM, and the MS Advisory Group. ABN guidance on the use of disease-modifying therapies in multiple sclerosis in response to the threat of a coronavirus epidemic. London: Association of British Neurologists; 2020. 